\title{
Application of nanofiltration membranes for removal of surfactants from water solutions
}

\author{
Izabela Kowalska $^{1}$, and Aleksandra Klimonda ${ }^{1, *}$ \\ ${ }^{1}$ Wroclaw University of Science and Technology, Faculty of Environmental Engineering, Wybrzeże \\ S. Wyspiańskiego 27, 50-370 Wrocław
}

\begin{abstract}
The objective of the study was to compare effectiveness of nanofiltration (NF) process for treatment aqueous solutions containing various types of surfactants (anionic, cationic and non-ionic). The experiments were conducted with the use of Microdyn-Nadir ${ }^{\mathbb{B}}$ nanofiltration membranes (NP010 and NP030). The effect of surfactant type, its concentration and membrane cut-off on the process parameters (retention coefficient and permeate flux) was assessed. The experiments showed that separation of anionic and cationic surfactants depended on their concentration in the feed solutions. The retention coefficient of anionic surfactant ranged from 54 to $81 \%$ (NP010) and from 64 to $80 \%$ (NP030), while rejection of cationic surfactant varied from 48 to $85 \%$ (NP010) and from 51 to $88 \%$ (NP030). The values of retention coefficient of non-ionic surfactant were in the range of $69-77 \%$ and $79-88 \%$ for NP010 and NP030, respectively; and to a much lesser extent were depended on its concentration in the feed solutions in comparison with anionic and cationic compounds. Membrane characterized by smaller value of cut-off (NP030) allowed to obtain higher retention coefficients of surfactants. The membrane permeability deterioration was observed with the increase of surfactants concentration in the treated solutions. In all experiments, a sharp decline of the permeate flux was noticed for concentration below the $\mathrm{CMC}$ values.
\end{abstract}

\section{Introduction}

Surfactants are organic compounds that exhibit surface activity. Due to their amphiphilic structure, surface active agents lower the surface tension between two phases (two liquid or liquid and solid phases) and induct wetting, foaming, emulsifying and dispersing properties of the solutions [1]. A molecule of the surfactant contains both hydrophobic and hydrophilic unit. The hydrophilic part enables molecule to solubilize in polar liquids, while the hydrophobic portion allows the solubilisation in nonpolar liquids. Depending on the hydrophilic unit charge, surfactants are classified into four groups: nonionic (0), anionic (-), cationic $(+)$ and amphoteric $( \pm)[2]$.

Due to the surface properties, surfactants are being used in numerous fields of the economy. The main applications of surfactants are: household detergents, toiletries,

*Corresponding author: aleksandra.klimonda@pwr.edu.pl 
personal and body care products, cosmetics, industrial cleaning processes as well as textile, pulp and paper or construction industries [3]. In 2016, the surfactants market was estimated to USD 30.64 billion [4] and it is expected to reach USD 46.20 billion by 2022 [5]. The commercially most significant type of surfactants are anionic surfactants, which share more than $50 \%$ of the global market [6]. Value of the surfactant market in Poland in 2009 was estimated to USD 165 million [7].

Such wide range of application results in discharging surfactants into sewage system or directly into surface water [8]. Surface active agents occur both in municipal and industrial wastewater [2]. Large amounts of surfactants in sewage stream may result in disorder of biological treatment (activated sludge process) [9], hence surfactant concentration in industrial wastewater discharged into sewage systems in Poland cannot exceed $15 \mathrm{mg} / \mathrm{dm}^{3}$ and $20 \mathrm{mg} / \mathrm{dm}^{3}$ for anionic and non-ionic surfactants, respectively [10].

Insufficient wastewater treatment or direct releasing of contaminated sewage into water environment contribute to pollution of water bodies by surfactants. In the surface water, surfactants may reveal injurious effects to living organisms on account of their toxicity and their ability to solubilize of toxic organic compounds [11]. In surfactant-polluted water, oxygen permeation is limited [12]. Thus, the growth and development of the living organisms as well as self-cleaning processes are inhibited. When the surfactants concentration exceeds $0.1 \mathrm{mg} / \mathrm{dm}^{3}$, the foaming of the water is observed [12].

In view of significant impact of surfactants on the environment, their removal from wastewater is indispensable. Additionally the economic factors lead to research on the recovery of surfactants in purpose of their reuse in manufacturing plants [13]. Pressuredriven membrane processes are employed in many fields of environmental engineering, mainly in water and wastewater treatment plants. Many studies relate to the usability of membrane techniques for removal of surface active agents from aqueous solutions [14-15]. Microfiltration (MF) is used as a pre-treatment method which enables removal of suspended solids before the main process which may be ultrafiltration (UF), recommended for the treatment of the micellar solutions (with critical micellar concentration, CMC) or nanofiltration (NF) which is regarded as an effective method in removal of surfactants in concentration below the CMC (surfactants monomers) [16-18].

The objective of experimental research was to compare effectiveness of nanofiltration (NF) process for purification of aqueous solutions containing various types of surfactants (anionic, cationic and non-ionic) at wide range of concentration.

\section{Experimental}

\subsection{Solutions}

Anionic (Triton QS-44, polyether phosphate ester), cationic (CTAB, cetyltrimethylammonium bromide) and non-ionic (Triton X-100, polyethylene glycol tert-octylphenyl ether) surfactants have been chosen for the experiments. The concentration of the surfactants in feed solutions was equal to $0.025,0.1,0.25,0.5,0.75,1,2$ and $3 \mathrm{CMC}$ values. The characteristics of surface active agents is shown in Table 1.

Table 1. Characteristics of surfactants.

\begin{tabular}{|c|c|c|c|}
\hline Surfactant & Triton QS-44 & CTAB & Triton X-100 \\
\hline Type & Anionic & Cationic & Non-ionic \\
\hline CMC, $\mathrm{mg} / \mathrm{dm}^{3}$ & $250\left(22^{\circ} \mathrm{C}\right)$ & $335\left(22^{\circ} \mathrm{C}\right)$ & $165\left(22^{\circ} \mathrm{C}\right)$ \\
\hline Aggregation number & - & 170 & $100-155$ \\
\hline Diameter of the micelle, $\mathrm{nm}$ & - & 3.5 & 8.5 \\
\hline
\end{tabular}


The concentrations of the surfactants in aqueous solutions were determined using the potentiometric titration method on the apparatus 785 DMP Titrino.

\subsection{Nanofiltration process}

Flat-sheet nanofiltration Microdyn-Nadir ${ }^{\circledR}$ membranes (NP010 and NP030) made of polyethersulfone (PES) were used in the experiments. Membrane varied in molecular weight cut-off (MWCO) [17]. The parameters of investigated membranes are given in Table 2. The NF process was performed using a laboratory-scale system with an Amicon 8400 UF cell in a dead-end filtration regime. The effective surface area of the membrane was $45,4 \mathrm{~cm}^{2}$. The volume of the filtration cell amounted to $350 \times 10^{-6} \mathrm{~m}^{3}$. The process was performed under the transmembrane pressure (TMP) of $0.20 \mathrm{MPa}$.

Table 2. Characteristics of Microdyn-Nadir ${ }^{\circledR}$ nanofiltration membranes.

\begin{tabular}{|c|c|c|c|c|c|}
\hline $\begin{array}{c}\text { Membrane } \\
\text { type }\end{array}$ & $\begin{array}{c}\text { Membrane } \\
\text { polymer }\end{array}$ & $\begin{array}{c}\mathbf{N a}_{2} \mathbf{S O}_{4} \\
\text { retention } \\
\text { (\%) }\end{array}$ & $\begin{array}{c}\text { Pore radius } \\
\text { (nm) }\end{array}$ & $\begin{array}{c}\text { MWCO } \\
\text { (Da) }\end{array}$ & $\begin{array}{c}\text { Surface } \\
\text { charge }\end{array}$ \\
\hline NP010 & polyethersulfone & $25-40$ & $0.80-1.29$ & $1010-1400$ & negative \\
\hline NP030 & polyethersulfone & $80-95$ & $0.59-0.93$ & $500-700$ & negative \\
\hline
\end{tabular}

Prior to the first filtration cycle, the brand-new membranes were soaked in distilled water for 24 hours and then the volume flux was measured under different transmembrane pressures in a range of $0.05-0.30 \mathrm{MPa}$. After each filtration cycle, the membranes were cleaned with the use of $0.1 \mathrm{M} \mathrm{NaOH}$ and treated with deionised water.

During the experiments, retention coefficient of surfactants and permeate volume flux were determined. To designate the membranes susceptibility to fouling, relative flux $\left(\mathrm{J} / \mathrm{J}_{0}\right)$ was evaluated.

\section{Results and discussion}

\subsection{Transport properties}

Fig. 1 shows the effect of applied transmembrane pressure on membranes transport properties measured as a distilled water volume flux. Three brand-new membranes NP010 and three NP030 were examined.

It was noticed that membrane permeability increased with the applied pressure. The volume flux varied from $5.9 \mathrm{dm}^{3} / \mathrm{m}^{2} \mathrm{~h}$ (TMP $=0.05 \mathrm{MPa}$ ) to $42.2 \mathrm{dm}^{3} / \mathrm{m}^{2} \mathrm{~h}$ $(\mathrm{TMP}=0.30 \mathrm{MPa})$ for membrane NP010 and from $1.1 \mathrm{dm}^{3} / \mathrm{m}^{2} \mathrm{~h}(\mathrm{TMP}=0.05 \mathrm{MPa})$ to $7.5 \mathrm{dm}^{3} / \mathrm{m}^{2} \mathrm{~h}(\mathrm{TMP}=0.30 \mathrm{MPa})$ for membrane NP030. The NP010 membranes obtained higher distilled water volume flux which is in accordance to membrane pore radius and MWCO reported by literature data [17].

The relative flux obtained after 60 min of the NF process is presented in Fig. 2. As can be seen, for all tested surfactants an increase of their concentration in the feed resulted in membrane permeability deterioration comparing with distilled water flux. During the filtration, a sharp decline of the membranes hydraulic properties was observed when the concentration of surfactants was below the CMC $\left(\mathrm{J} / \mathrm{J}_{0}\right.$ for membrane NP010 and concentration equal to $1 \mathrm{CMC}$ was $33 \%, 63 \%$ and $29 \%$ for Triton QS-44, CTAB and TRITON X-100, respectively; and for membrane NP030 and concentration equal to 1 CMC was $42 \%, 60 \%$ and $29 \%$ for Triton QS-44, CTAB and TRITON X-100, respectively). In concentration below the $\mathrm{CMC}$ value a phenomenon of surfactants monomer adsorption 
onto membrane pores occurs. Further increasing of surfactants concentration results in forming micelles which create polarization layer near the membrane surface. Thus, further decrease of membrane permeability is observed.

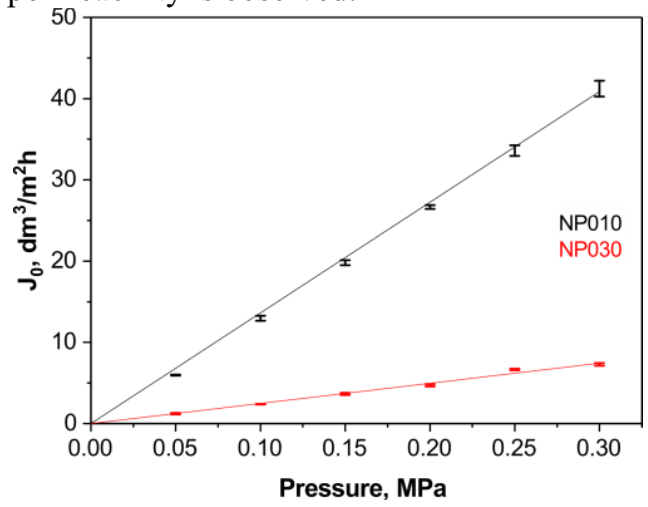

Fig. 1. Distilled water flux $v$ s transmembrane pressure.
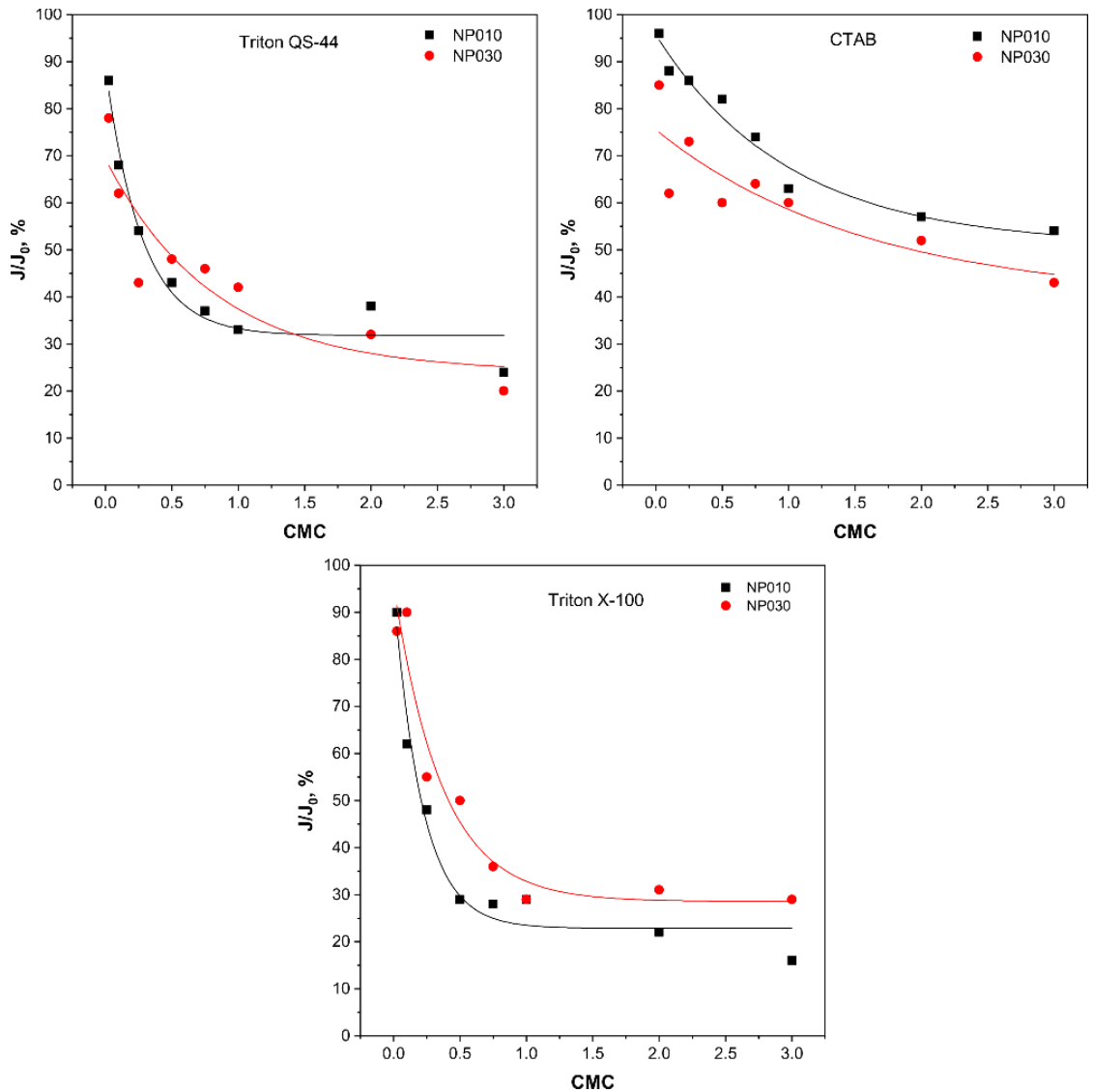

Fig. 2. Relative flux and $v s$ surfactants concentration during nanofiltration process (TMP $=0.20$ $\mathrm{MPa})$. 
During the filtration of non-ionic surfactant Triton X-100, membrane NP030 exhibited higher values of relative flux than membrane NP010 which corresponds with literature data. Kaya et. al [2] reported that membrane NF PES 10 (made of polyethersulfone, MWCO $=1000 \mathrm{Da}$ ) was more fouled than membrane $\mathrm{N} 30 \mathrm{~F}$ (polyethersulfone, $\mathrm{MWCO}=400 \mathrm{Da}$ ) during the non-ionic surfactant filtration. It should be mentioned that correlation between membrane pore size and micelle diameter/ monomer length affects process efficiency. Diameter of the membrane NP030 pore $(0.59-0.93 \mathrm{~nm}$ [17]) is considerably smaller than surfactant's particle size (diameter of Triton X-100 micelle is $8.5 \mathrm{~nm}$ ). As a result, adsorption of surfactants monomers in membrane pores is impeded. Membrane NP030 allowed to provide relative flux in the range from $86 \%(0.025 \mathrm{CMC})$ to $0.29 \%\left(3 \mathrm{CMC}\right.$ ) when for membrane NP010 (pore radius $0.80-1.29 \mathrm{~nm}$ ) values of $\mathrm{J} / \mathrm{J}_{0}$ varied from $90 \%(0.025 \mathrm{CMC})$ to $16 \%(3 \mathrm{CMC})$.

It was observed that presence of cationic surfactant (CTAB) in feed solutions exhibit the lowest influence on membranes transport properties. Obtained relative flux varied from $96 \%(0.025 \mathrm{CMC})$ to $54 \%(3 \mathrm{CMC})$ and from $85 \%(0.025 \mathrm{CMC})$ to $43 \%(3 \mathrm{CMC})$ for NP010 and NP030 membrane, respectively.

\subsection{Separation properties}

Fig. 3 shows the retention coefficient versus surfactant concentration during the filtration.
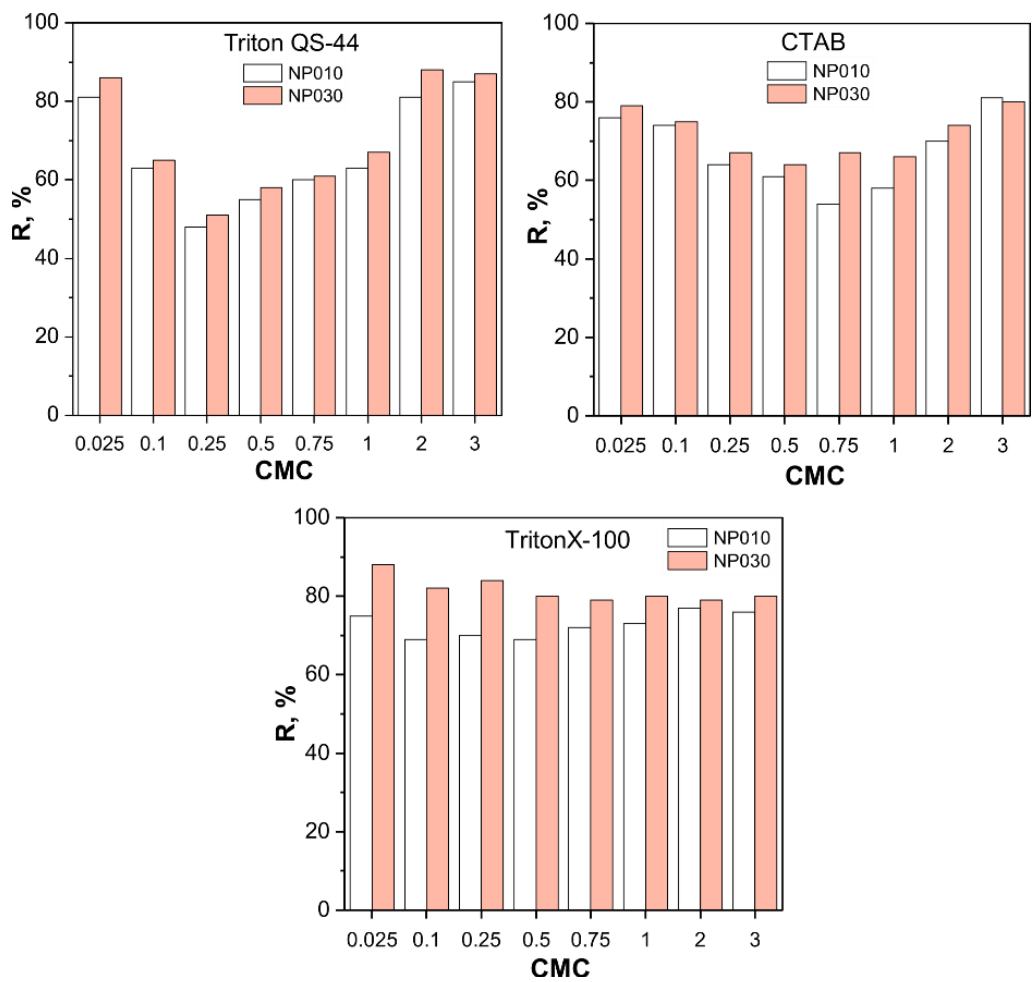

Fig. 3. Retention coefficient $v s$ surfactants concentration during nanofiltration process (TMP $=0.20$ $\mathrm{MPa})$.

It should be mentioned that the best separation properties of anionic and cationic surfactant were obtained both for very low and the very high concentration in the feed. 
Monomer adsorption on membrane surface and within the pores effected on good separation at low concentration [18]. When the concentration increased in the range below the $\mathrm{CMC}$, membrane selectivity deterioration was observed. However, for the concentration above the $\mathrm{CMC}$, the improvement of the retention due to forming of the micelles was noticed. Literature reports partially confirm the results obtained [19]. Membrane filtration of anionic surfactant alkyl-polyether-sulfate (at $20^{\circ} \mathrm{C}$ ) in a wide range of concentration (below $\mathrm{CMC}$ and far above $\mathrm{CMC}$ ) resulted in retention coefficient from $92 \%$ (below the $\mathrm{CMC})$ to $>98,5 \%(\sim 3 \mathrm{CMC})$.

\section{Conclusions}

The experimental research showed that nanofiltration process is a satisfactory method for removal of all tested types of surfactants from low-concentration solutions. In all experiments, membrane characterized by smaller MWCO allowed to obtain higher efficiency of surfactants separation.

The experimental results demonstrated that the concentration of surfactant in solution is a crucial parameter which significantly affects on the process efficiency. Increasing dosage of surface active agent in the feed resulted in deterioration of membranes' permeability and strongly affected on separation properties which differed greatly under various values of concentration.

There is a correlation between membrane pore diameter and surfactant molecule size. Removal of the non-ionic surfactant in the process with membrane NP030 exhibited the highest values of retention coefficient - in the rage of $79-88 \%$ - due to the significant differences in the monomer length and the membrane pore diameter.

This work was supported by a grant (No. 0401/0064/16) from the Department of Environmental Engineering, Wrocław University of Science and Technology.

\section{References}

1. K. Majewska-Nowak, I. Kowalska, M. Kabsch-Korbutowicz, Desalination 184 (2005)

2. Y. Kaya, C. Aydiner, H. Barlas, B. Keskinler, J. Membr. Sci. 282 (2006)

3. R.J. Farn, Chemistry and Technology of Surfactants (Blackwell Publishing Ltd, New Delhi, 2006)

4. http://www.researchandmarkets.com/reports/3927849/surfactants-market-by-typeanionic-non-ionic

5. http://www.researchandmarkets.com/reports/3640162/surfactants-market-analysis-byproduct-by\#relb0

6. Market Study: Surfactants (Ceresana, 2nd ed., 2015)

7. Prospectus of the PCC Exol dated June 27, 2012

8. T. Ivankovic, J. Hrenovic, Arh Hig Rada Toksikol 61 (2010)

9. A. Dereszewska, S. Cytawa, R. Tomczak-Wandzel, K. Medrzycka, Pol. J. Environ. Stud. 24, 1 (2015)

10. Journal of Laws of 2016, item 1757 (in Polish)

11. R. Romczask-Wandzel, A. Dereszewska, S. Cytawa, K. Medrzycka, Research and application of new technologies in wastewater treatment and municipal solid waste disposal in Ukraine, Proceedings of a Polish-Swedish-Ukrainian seminar, Lviv Ukraine, October 26-28, 2006 
12. C.L. Yuan, Z.Z. Xu, M.X. Fan, H.Y. Liu, Y.H. Xie, T.Zhu, J. Chem. Pharm. Res. 6, 7 (2014)

13. H. Byhlin, A. Jonsson, Desalination 151 (2002)

14. L.A.T. Nguyen, M. Schwarze, R. Schomacker, J. Membr. Sci. 493 (2015)

15. I. Kowalska, Pol. J. Environ. Stud. 21, 3 (2012)

16. L. Suarez, M.A. Diez, R. Garcia, F.A. Riera, J. Ind. Eng. Chem. 18 (2012)

17. Z. Kovács, W. Samhaber, Membrántechnika 12 (2008)

18. I. Kowalska, Desalination 221 (2008)

19. A.C. Archer, A.M. Mendes, R.A.R. Boaventura, Environ. Sci. Technol. 33 (1999) 